\title{
Chromoblastomycosis (possibly Cladosporium) of the breast in an English woman
}

\author{
L. HENRY AND A. P. ROSS \\ From the Department of Pathology, St. Bartholomew's Hospital, London
}

SYNOPSIS A case is reported of an English woman who presented with a mass in the breast which was locally excised. Histological studies revealed a giant-cell granulomatous inflammation involving the duct system and a fungus showing brown pigmentation was demonstrated in the lesions. This was not grown in culture but the morphological appearance suggested classification in the genus Cladosporium. The relation of this to the more usual forms of cutaneous chromoblastomycosis is discussed.

Chromoblastomycosis is an infection with one of a number of species of fungi showing a brown pigmentation. The infection is usually a skin lesion following trauma and, although reported from many areas, is mainly confined to tropical countries. Four cases have been reported from Britain. The present paper concerns a fifth case, one of deep infection of the breast in a previously healthy English woman due to a pigmented fungus.

\section{CASE REPORT}

The patient was a 47-year old woman, an office cleaner who lived in London. She had never been abroad. She complained of a swelling in the right breast of some six weeks' duration. A mild 'gathering' sensation was noted but there were no other symptoms. She was referred to Mr. E. G. Tuckwell at St. Bartholomew's Hospital with a provisional diagnosis of carcinoma.

Further enquiry revealed no other symptoms. She had breast-fed four children, the youngest aged $3 \frac{1}{2}$ years, with no infective complications. Menstruation was normal. There was no discharge from the nipple and no history of trauma to the breast. The past history was not significant.

On examination she had pendulous breasts and in the upper and inner quadrant on the right side there was a firm mass approximately $10.0 \mathrm{~cm}$. in diameter with illdefined edges. There was no superficial or deep attachment but the overlying skin showed a mild oedema and erythema. The axillary nodes were palpable, being slightly larger on the right. The nipple was normal.

At operation the mass was excised locally. The specimen was cut open revealing multiple small abscesses and a swab was taken from the pus. The wound was closed with drainage.

The specimen was a portion of breast tissue measuring

Received for publication 9 August 1966
$12 \times 10 \times 6 \mathrm{~cm}$. with no attached skin. The central portion was occupied by a firm mass having an irregular outline and measuring approximately $5 \mathrm{~cm}$. in diameter. The cut surface showed dense grey fibrous tissue extending into the surrounding breast and containing multiple small discrete abscesses which contained greenish yellow pus (Fig. 1). Serial slicing showed no evidence of any neoplasm.

Post-operatively the patient developed a mild pyrexia but no antibiotics were given and the temperature returned to normal. The wound healed after producing a serous discharge and she was discharged after 17 days. Four weeks later she returned with the lesions of erythema nodosum on both legs. At this time the E.S.R. was $90 \mathrm{~mm}$. /hr. (Westergren), the haemoglobin 11. g./100 ml. and the white count $6,300 / \mathrm{c}$. mm. with a normal differ-

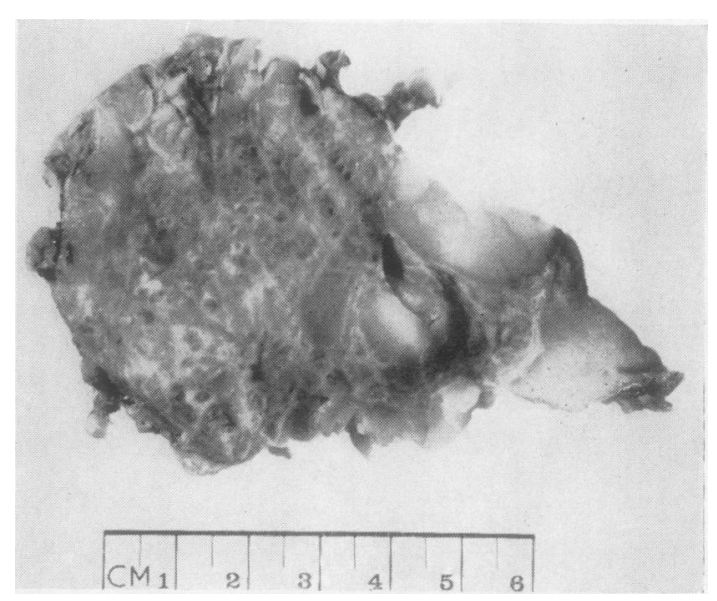

FIG. 1. Macroscopic view of the gross specimen showing focal abscess formation and fibrosis which extends into the surrounding breast tissue. 
ential. The chest radiograph was normal, and the antistreptolysin $\mathrm{O}$ titre was not raised. The patient is being kept under observation and no specific therapy has been given.

\section{LABORATORY STUDIES}

The swab taken at operation was cultured and showed scanty micrococci. After replating on Sabouraud's medium no growth was obtained after six weeks' incubation. A swab from the drainage site also gave a scanty growth of micrococci but cultures for fungus were again negative.

MiCrosCoPIC PATHOLOGY Sections from several areas revealed multiple giant-cell granulomas with focal abscess formation and dense fibrosis (Fig. 2). In most areas the lesions were related to the duct system but other ducts were merely surrounded by an active chronic inflammation or by oedema. At the periphery of the lesion the ducts were normal.

The granulomas contained a variety of cells. Some of the giant cells were of the Langhans type and there were abundant plasma cells, eosinophils, lymphocytes, and, in the areas of abscess formation, polymorph leucocytes. In all of the slides examined a brown fungus was demonstrated in the lesions. No bacteria were revealed with Gram's stain and stains for acid-fast bacilli were negative.

IDENTIFICATION OF THE FUNGUS In the absence of cultural data, identification rests solely on morphological grounds. In all areas the fungus was present in the form of brown chlamydospores occurring singly or in clumps (Fig. 3). Many of the organisms appeared to be within macrophages and Gram's stain showed non-pigmented fungal elements in such cells which were not identifiable with the haematoxylin and eosin stain. Periodic acid-Schiff and methenamine silver stains revealed the organism to be present in considerable numbers. In a few areas diploid forms occurred and occasionally a septate appearance was seen (Fig. 4) but no hyphae could be demonstrated and there was no evidence of true budding or sporulation.

In the cases of cutaneous chromoblastomycosis the organism is deeply pigmented with a thick refractile cell wall and showing septation in one or more planes. In most clinical cases the fungus belongs to the genus Hormodendrum or Phialophora but it is not considered that the present case falls into this category. The pigmentation is lighter, the cell wall is thinner, and the manner of septation is more like that of Cladosporium. This is a common pigmented fungus and Binford, Thompson, and Gorham (1952) quote Saccardo's Sylloge Fungorum

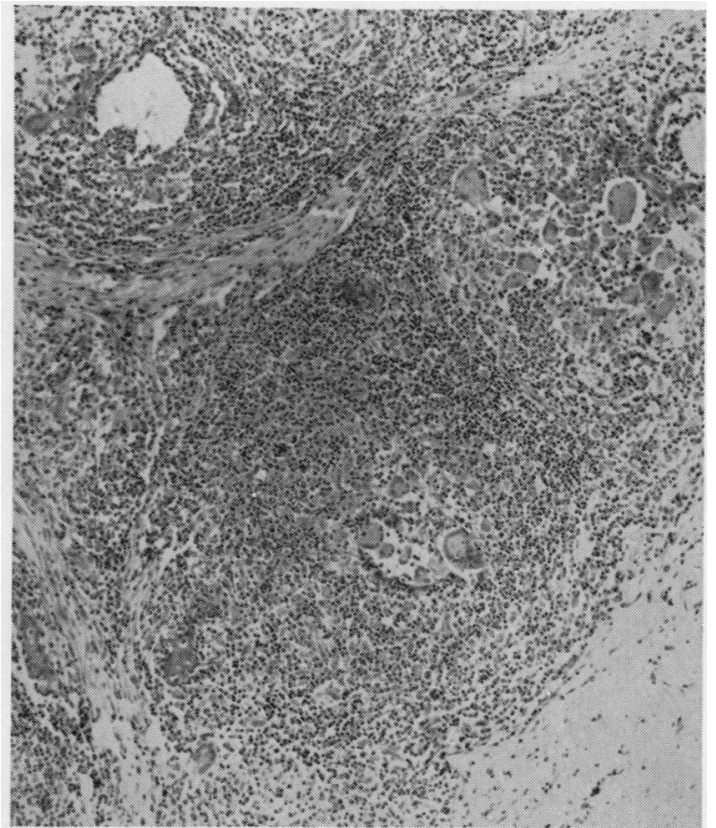

FIG. 2. Section of the lesion showing areas of giant-cell granulomatous inflammation. Haematoxylin and eosin $\times$ 65 .

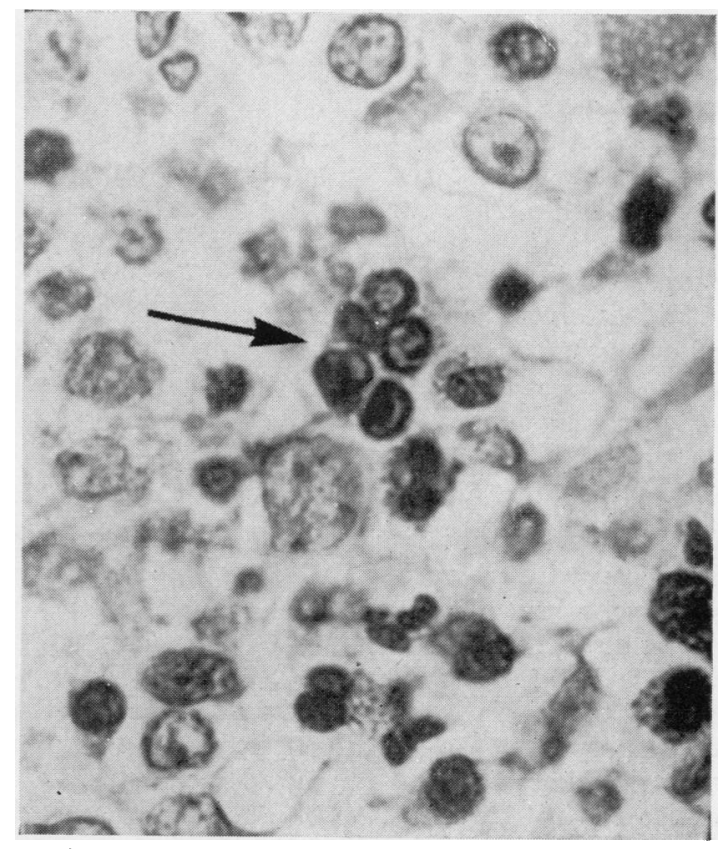

FIG. 3. A group of fungi in one of the lesions. In the section these have a distinct brown pigmentation. Haematoxylin and eosin $\times 1,100$. 


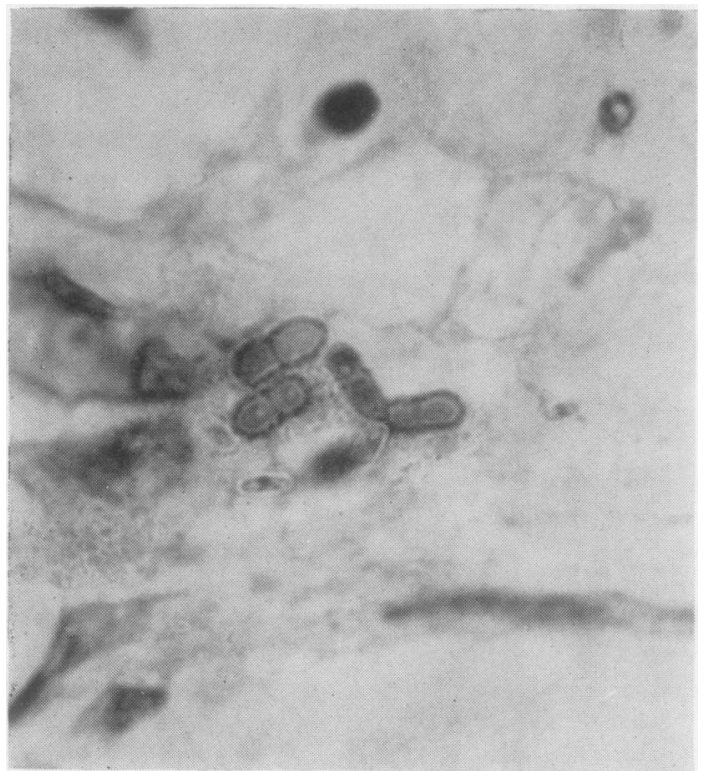

FIG. 4. A group of fungi showing transverse septation. Haematoxylin and eosin $\times 1,100$.

as listing 259 species. These authors reported the first case of a brain abscess due to a previously unrecognized species, Cladosporium trichoides. The tissue-phase of this fungus shows abundant hyphal forms. These were not seen in the present case but otherwise the morphology is similar. A further species Cladosporium wernecki is a known pathogen, being the causative agent of Tinea nigra. The only evidence for considering this possibility is the resemblance of Fig. 4 in the present case to the illustration given by Conant, Smith, Baker, Callaway, and Martin (1954), but there is no reason why other species should not show this morphology and be pathogenic when introduced into the tissues. However, in the absence of cultural data identification of this fungus can go no further than its provisional placing within the genus Cladosporium.

\section{DISCUSSION}

Chromoblastomycosis is an inclusive term signifying infection with a variety of dematiaceous fungi showing a brown pigmentation. In the usual form of the disease the organism proves to be Hormodendrum pedrosoi, $\boldsymbol{H}$. compactum, or Phialophora verrucosa. Other species are less common, but as the tissue phases are identical, identification rests upon their isolation in culture. The mycological aspects are discussed by Carrión (1950). Although reported from many countries it is almost exclusively a tropical disease. Cases have been reported from Australia (Saxton, Hatcher, and Derrick, 1946) and from the U.S.A., predominantly in the southern States although the first case occurred in Boston (Lane, 1915). The organism enters by cutaneous trauma and thus the disease commonly affects the extremities of male agricultural workers. The lesions are usually superficial but a subcutaneous abscess may occur without the skin being involved (Kempson and Strenberg, 1963). Lymphatic spread may occur but metastatic lesions are rare (Carrión and Koppisch, 1933; Fukushiro, Kagawa, Nishiyama, and Takahashi, 1957; Sasano, Okamoto, Takahashi, and Suzuki, 1961). The latter authors reported a remarkable case of a 3-year-old boy, who both smoked and chewed tobacco, dying from a disseminated infection.

However, in a second type of infection a brain abscess may occur in the absence of skin lesions. When isolated, the organism in these cases is usually identified as Cladosporium trichoides. The first case was recorded by Binford et al. (1952) and 14 other cases were quoted by Symmers (1960a).

The disease is rare in England and only four cases have been reported. In addition a further unreported case of cutaneous infection in a West Indian immigrant has recently been seen in this Department. Crow and Riddell (1954) found Hormodendrum pedrosoi in a lesion on the elbow of a West Indian living in this country for two years but with a total history of twelve years' duration. Symmers (1960b) quotes a similar case in a Jamaican and also reported the disease in a patient from Ceylon. The first case of the disease in an English person who had never left the country was also recorded by Symmers (1960a). The patient was a 22-year-old woman treated for 11 weeks with cortisone for polyarteritis nodosa. Death followed a left hemiplegia and at necropsy fungi resembling Cladosporium trichoides were seen in the brain lesion.

The present case is the first from any source where such a fungus has produced a deep infection of the breast. The relation of the lesions to the duct system suggests the nipple as the portal of entry. The patient was not under treatment with antibiotics, steroids, or cytotoxic drugs and the presence of a plasma cell response in the lesions with extensive phagocytosis of the organisms probably indicates a normal immunological potential. The development of erythema nodosum may mark the onset of delayed hypersensitivity. Species of Cladosporium are common in nature but the large number of organisms and their relation to the granulomas indicate a pathogenic role in this instance.

The nomenclature of these fungi is confusing. In the older literature the genus Cladosporium is used synonymously with Hormodendrum and each individual species tends itself to have a number of 
synonyms. Similarly, the term chromoblastomycosis is used by some authors to cover all forms of infection with these fungi while others would confine its use to the classical cutaneous form of the disease only. However, pending further taxonomic clarification it is proposed, following Symmers (1960a), to classify this case provisionally as one of chromoblastomycosis of the breast possibly due to a species of Cladosporium.

Thanks are due to Mr. E. G. Tuckwell for permission to publish this case report and to Dr. R. W. Riddell for help with the identification of the fungus. The illustrations were provided by Mr. P. Crocker and the Department of Medical Illustration, St. Bartholomew's Hospital.

\section{REFERENCES}

Binford, C. H., Thompson, R. K., and Gorham, M. E. (1952). Amer. J. clin. Path., 22, 535.

Carrión, A. L. (1950). Ann. N. Y. Acad. Sci., 50, 1255.

-, and Koppisch, E. (1933). Puerto Rico J. publ. Hith, 9, 169.

Conant, N. F., Smith, D. T., Baker, R. D., Callaway, J. L., and Martin, D. S. (1954). Manual of Clinical Mycology, 2nd ed., p. 287. Saunders, Philadelphia.

Crow, K. D., and Riddell, R. W. (1954). Proc. roy. Soc. Med., 47, 655.

Fukushiro, R., Kagawa, S., Nishiyama, S., and Takahashi, H. (1957). Presse méd., 65, 2142.

Kempson, R. L., and Sternberg, W. H. (1963). Amer. J. clin. Path., 39, 598.

Lane, C. G. (1915). J. cutan. Dis., 33, 840.

Sasano, N., Okamoto, T., Takahashi, T., and Suzuki, S. (1961). Tohoku J. exp. Med., 73, 180.

Saxton, W. J., Hatcher, F., and Derrick, E. H. (1946). Med. J. Aust., 1,695 .

Symmers, W. St. C. (1960a). Brain, 83, 37.

(1960b). J. clin. Path., 13, 287. 